\title{
AVALIAÇÃO MICROBIOLÓGICA EM PROCESSOS DE COMPOSTAGEM DE RESÍDUOS AGROINDUSTRIAIS VISANDO A PRODUÇÃO DE COMPOSTO ORGÂNICO DE QUALIDADE
}

\author{
Fabiane Fernanda Czapela1', Carina da Silva Rodrigues², Simone Maria \\ Golunski ${ }^{3}$, Eduardo Pavan Korf ${ }^{4}$ e Helen Treichel ${ }^{5}$
}

\begin{abstract}
Resumo: A preocupação com a geração de resíduos provenientes da produção de alimentos tem se intensificado. Isto porque estes resíduos possuem altas concentrações de matéria orgânica, que causam danos se não forem tratados adequadamente. Uma forma de tratar de maneira eficaz estes resíduos é por meio da compostagem. O objetivo deste trabalho foi contribuir para a melhoria dos processos de compostagem de resíduos agroindustriais gerados em pequenas propriedades rurais. Para isso, realizou-se uma avaliação microbiológica em processos de compostagem em pequena escala em amostras de três sistemas distintos localizados na região sul do Brasil, para verificar a presença de microrganismos potencialmente patogênicos como E. coli, Salmonella spp., fungos filamentosos e leveduriformes. Foi verificado que nos sistemas com controles de aeração a presença de patogênicos foi menor apenas para E.coli, porém houve permanência de Salmonella spp. e fungos nos três sistemas avaliados apontando para a necessidade de melhoria nos sistemas de compostagem utilizados pelas pequenas propriedades rurais. A presença de Salmonella nos compostos dos três sistemas evidencia o risco à saúde pública e a necessidade de padronização e melhoria do processo de compostagem hoje utilizados.
\end{abstract}

Palavras-chave: Composteira. Microrganismos potencialmente patogênicos. Fertilizante orgânico.

\section{Introdução}

$\begin{array}{rccr}\text { Nos últimos anos houve um } \\ \text { crescimento } & \text { na mecanização }\end{array}$
desenvolvimento da agricultura e pecuária. Isto por conta do crescimento populacional e consequentemente, aumento da demanda de alimentos (ISMAEL et al., 2013). Nesse contexto, a segurança alimentar e a nutrição estão intimamente relacionadas com a procura por alimentos. Isto porque, caso um alimento não apresente boas condições de consumo, o mesmo pode acarretar em diferentes formas de desnutrição, bem como causar riscos à saúde pública (FAO, 2020). Por isso é importante avaliar a qualidade dos alimentos que serão consumidos, evitando danos futuros.

Atrelado ao aumento da produção agrícola e pecuária e a preocupação com as questões ambientais, tem se discutido a otimização dos recursos nutricionais, ou seja, produzir alimentos de forma sustentável e com a qualidade desejada. Também há uma enorme preocupação com a geração de resíduos provenientes da produção de alimentos, já que estes resíduos possuem em sua composição altas concentrações de matéria orgânica, que se destinada de forma inadequada podem causar prejuízos ao meio ambiente, além de contribuir com 0 surgimento de vetores causadores de doenças (MENDES; CINTRÃO, 2004; MARAGNO; TROMBIN; VIANA, 2007).

Os resíduos provenientes de atividades agroindustriais possuem como características principais o fato de serem biodegradáveis e possuírem altos teores de umidade, podendo desta forma, serem encaminhados a processos de valoração de resíduos (CESARO et al., 2019). Um dos processos destinados a recuperar e valorar estes resíduos é o processo de compostagem. Trata-se de um método que visa estabilizar biologicamente o resíduo em condições aeróbias, gerando um produto

\footnotetext{
ㅌE-mail: fabiczapela@gmail.com

2E-mail: k.karin.karina@hotmail.com

${ }^{3}$ E-mail:simonegolunski@gmail.com

${ }^{4}$ E-mail: eduardokorf@gmail.com
} 


\section{REA - Revista de estudos ambientais (Online) v.22, n. 1, p.24-34, jan./jun. 2020}

melhorado para uso no solo (ALVARENGA et al., 2007; PÉREZ et al., 2007; ALVARENGA et al., 2015; MEENA et al., 2016).

A compostagem depende de diversos fatores que influenciam diretamente na qualidade do composto final. Um destes fatores é o suprimento de oxigênio que favorece a ação dos microrganismos e consequentemente a obtenção de um composto orgânico de qualidade (ONWOSI et al., 2017; CESARO et al., 2019). O fornecimento de oxigênio está relacionado com a atividade dos microrganismos envolvidos na hidrólise dos resíduos, além disso, um aumento ou diminuição deste fornecimento na faixa limite pode afetar a atividade, desacelerando-a, por exemplo (MEJIAS et al., 2017).

O fornecimento de oxigênio pode afetar outros parâmetros envolvidos no processo de compostagem como a temperatura e o teor de umidade. Baixos teores de oxigênio sugerem baixas taxas de degradação e redução significativa da temperatura, afetando a atividade microbiana (GUO et al., 2012). Dessa forma, o mecanismo de aeração final é um dos principais fatores que influenciam na qualidade do composto (CHOWDHURY et al., 2014; FAVERIAL et al., 2016; RASAPOOR; ADL; POURAZIZI, 2016 ).

A compostagem em pequena escala é uma das formas encontradas para 0 tratamento de resíduos orgânicos em pequenas propriedades. Entre as vantagens de se utilizar esta técnica destacam-se a economia de energia e de custos, possibilidade de emprego do composto na fertilização do solo, para a agricultura e jardinagem; subsequente redução da poluição do ar e das águas subterrâneas, evitando-se a contaminação ambiental, além de contribuir para a melhoria continuada da qualidade do solo, dentre outras (LIMA et al., 2008; WANGEN; FREITAS, 2010).

No entanto, para que o composto possa ser utilizado na agricultura, é necessário que apresente características adequadas, para serem empregados como condicionadores de solo, disponibilizando nutrientes às plantas, e consequentemente transformando um problema de grande expressão em uma ótima solução. No entanto, sendo um processo de pequena escala, os parâmetros como umidade, aeração, temperatura, tamanho das partículas, concentração de nutrientes e $\mathrm{pH}$ devem ser monitorados de forma adequada pois um dos problemas que surgem em pequena escala é a contaminação por microrganismos potencialmente patogênicos (PEREIRA, 2013).

Estes microrganismos são considerados perigosos para a saúde pública, pois, principalmente quando é praticada a compostagem em pequena escala, controlálos com base na temperatura pode não ser eficaz para a remoção total. Além disso, é necessário um rígido controle dos parâmetros umidade e aeração para obtenção de um composto de boa qualidade, bem como a manutenção da temperatura e o tempo de maturação do processo (FLORES, 2011).

Do ponto de vista biológico, conforme afirma Kiehl (1985), os estercos de animais apresentam uma elevada quantidade de microrganismos, bactérias, como E. Coli, Salmonella spp., protozoários tais como Giardia e Cryptosporidium e ainda nematóides como Ascaris spp, além de fungos e leveduras (AUGUSTO, 2016). O esterco fresco é rico em bactérias que vivem no aparelho digestivo do animal, e no início da fermentação observa-se uma multiplicação de bactérias ao ponto de predominarem sobre os fungos e actinomicetes, e posteriormente, a quantidade de bactérias se reduz em favor desses últimos. O esterco é um ótimo meio de cultura para os microrganismos, aumentando a quantidade de bactérias no solo quando 0 mesmo é adicionado como fertilizante. $O$ esterco também pode apresentar formas transmissíveis de parasitos como ovos, larvas, cistos e oocistos (MARROCOS et al., 2012).

Desta forma, aplicando-se corretamente a técnica da compostagem em dejetos de origem animal, por exemplo, garante-se inúmeras vantagens. $O$ resíduo que é transformado em composto recebe um destino adequado preservando 0 meio ambiente, e pode ser comercializado, o que representa uma fonte de renda alternativa. Além disso, conforme ressalta Amorim, Lucas Júnior e Resende (2005), essas práticas contribuem para o saneamento, reduzindo o número de patógenos durante a fase termofílica da compostagem. Fase que se caracteriza por ser o início do processo da compostagem, durante a qual as temperaturas devem permanecer na faixa de 50 a $60 \stackrel{\circ}{ } \mathrm{C}$.

Pereira Neto e Stentiford (1992) ainda afirmam que a compostagem é o processo de tratamento de resíduos que apresenta maior flexibilidade operacional, aliado ao baixo custo e alta eficiência num só sistema. A compostagem pode ser adotada como 
solução adequada para os problemas relacionados aos resíduos orgânicos, apresentando benefícios ambientais e econômicos desde que comprovada a qualidade do composto de acordo com normas ambientais e sanitárias (ANDREOLLI, 1994).

Por isso, é importante avaliar a composição microbiológica em processos de compostagem em pequena escala. Isto porque existem legislações que regulamentam valores máximos permitidos para microrganismos potencialmente patogênicos tais como $E$. coli e Salmonella spp. em fertilizantes orgânicos. A Instrução Normativa $n^{\circ} 27$ que faz parte de um grupo de instruções do Ministério da Agricultura, Pecuária e Abastecimento (MAPA) e visa orientar a respeito dos valores máximos admitidos (BRASIL, 2006).

Desta forma justifica-se a importância de desenvolver este trabalho, visto que estes patógenos podem ser transferidos para alimentos que posteriormente poderão ser ingeridos pela população, ocasionando sérios problemas de saúde. Diante da problemática ambiental relacionada ao correto tratamento e disposição de resíduos, objetivou-se avaliar a atividade microbiológica dos sistemas de compostagem em pequena escala visando contribuir para a melhoria de processos de compostagem de resíduos agroindustriais gerados em pequenas propriedades, buscando a produção de composto orgânico de qualidade.

\section{Metodologia}

\section{1 Área e material de estudo}

O estudo foi desenvolvido com resíduos orgânicos (restos de alimentos, dejetos de aves, suínos e bovinos) obtidos de propriedades rurais da região sul do Brasil (Figura 1). Para isto contou-se com o auxílio do Centro de Apoio e Promoção da Agroecologia - CAPA, responsável por assessoramento técnico dos agricultores da região citada.

Figura 1 - Mapa representativo da área de estudo localizada na região Norte do Rio Grande do Sul e região Oeste de Santa Catarina

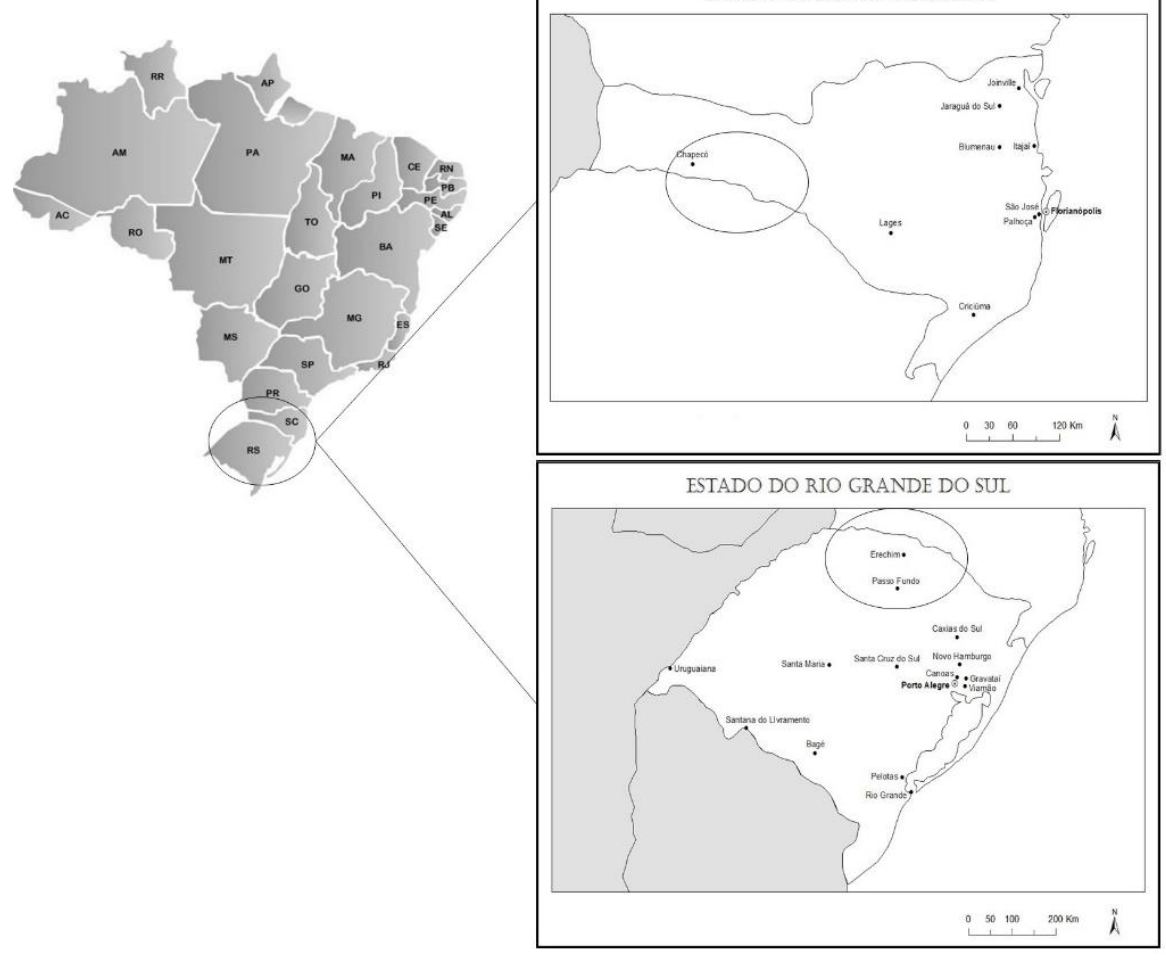

Latitude: $27^{\circ} 10^{\prime} 47^{\prime \prime} \mathrm{S}$ Longitude: $51^{\circ} 59^{\prime} 52^{\prime \prime} \mathrm{O}$ (Concórdia-SC)

Fonte: Google (2020)

Com relação ao clima da área de estudo, de acordo com a classificação climática de Koppen, ele se caracteriza por ser do tipo subtropical úmido, fazendo parte 
do grupo climático $\mathrm{Cfb}$, caracterizado por elevada umidade, porém, com verões amenos. A temperatura apresenta grande amplitude, oscilando entre mínimas negativas no inverno em algumas regiões e máximas próximas aos $40{ }^{\circ} \mathrm{C}$ no verão, sendo a temperatura média anual em torno de 14 a 22 ${ }^{\circ} \mathrm{C}$. Já com relação a precipitação pluviométrica, esta se caracteriza por ser bem distribuída gerando acumulados entre 1000 $\mathrm{mm}$ e $2000 \mathrm{~mm}$ anualmente.

Foram coletadas três amostras por sistema denominados de sistema 1 , sistema 2 e sistema 3 (Figura 2) após os tratamentos in loco, no período compreendido entre dezembro/2015 e fevereiro/2016, na estação do verão. As temperaturas mínimas do período de estudo estavam na faixa de $20^{\circ} \mathrm{C}$ e as temperaturas máximas em torno de 30 ${ }^{\circ} \mathrm{C}$. Em dezembro/2015 a temperatura média foi de $24{ }^{\circ} \mathrm{C}$, em janeiro/2016 de $25^{\circ} \mathrm{C}$ e em fevereiro a temperatura média foi de $22{ }^{\circ} \mathrm{C}$ para ambos locais de coleta (INMET, 2020). $O$ processo de amostragem seguiu recomendações da NBR 10.007 (ABNT, 2004). As análises foram realizadas nos laboratórios da Universidade Federal da Fronteira Sul, localizada na ERS 135, km 72 , na cidade de Erechim - RS.

Figura 2 - Sistemas de compostagem avaliados in loco e diferenças entre os mesmos

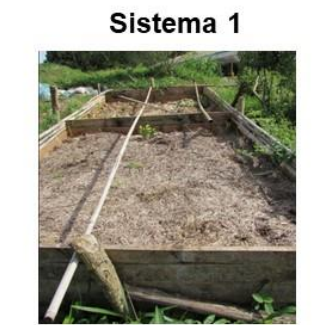

Sistema 2

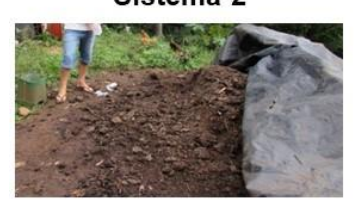

Sistema 3

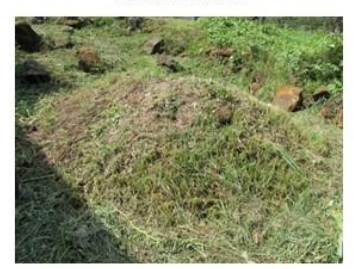

Fonte: Autores (2020)

A composteira do sistema 1 possui a vermicompostagem aliada a compostagem comum. Os resíduos permaneceram na composteira durante o período de quatro meses, até a obtenção do composto final. Neste caso foi realizado o controle da aeração do composto através do revolvimento realizado a cada 3 ou 5 dias. No entanto, este sistema não possui impermeabilização na parte inferior e nem cobertura na parte superior.

No sistema 2 foram realizados revolvimentos na leira de compostagem apenas quando necessário. Neste caso, os resíduos também permaneceram por aproximadamente quatro meses na
Sistemas de composteiras

Impermeabilizada Cobertura Revolvimento
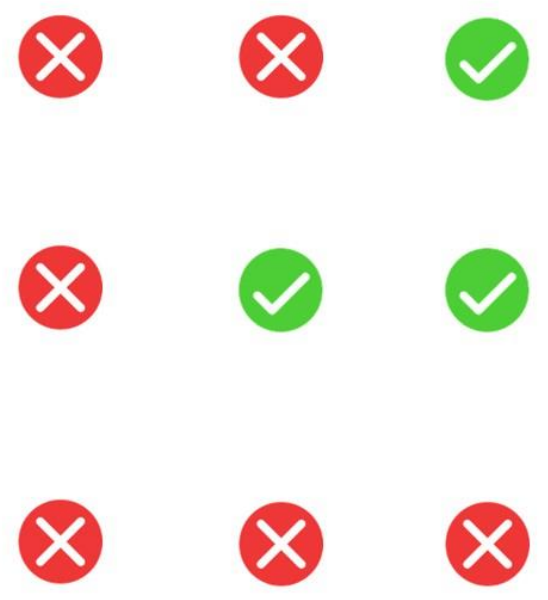

composteira. Nesta situação existe cobertura do sistema de compostagem.

Já no sistema 3 não eram realizados controles de parâmetros, como o revolvimento da pilha de compostagem para introdução de oxigênio. Além disso, o sistema não tinha cobertura adequada, ficando exposta às condições do tempo. Os resíduos permaneceram na composteira por quatro meses.

Os sistemas foram escolhidos aleatoriamente com o auxílio do CAPA, que presta assessoramento técnico aos agricultores dos locais de coleta escolhidos. Quanto ao tipo de sistema, estes são os mais comuns entre as pequenas propriedades rurais (NUNES, 2009). 


\subsection{Detecção de microrganismos potencialmente patogênicos}

Entre os microrganismos potencialmente patogênicos, foram avaliados E. coli, Salmonella spp., fungos filamentosos e leveduriformes (não filamentosos) a partir das amostras provenientes dos sistemas de tratamento descentralizado de resíduos rurais, de acordo com a metodologia descrita por Silva, Junqueira e Silveira (2001).

E. coli foi enumerada a partir da técnica do Número Mais Provável (NMP), de acordo com ABNT (1991), usando-se caldo E.C. Já Salmonella spp. foi avaliada utilizando-se Rappaport Vassiliadis Soy (RSV) como meio seletivo, seguido de caracterização em ágar Xilose Lisina Desoxicolato (XLD). Fungos filamentosos e leveduriformes foram avaliados a partir do crescimento em meio ágar batata dextrose (BDA), determinando assim o número de UFCS.

\section{Resultados}

\subsection{Detecção de microrganismos potencialmente patogênicos}

A Tabela 1 apresenta os resultados da avaliação microbiológica realizada para todas as amostras coletadas. Para E. coli e Salmonella spp. foram levados em consideração os valores máximos permitidos pela IN n²7 do MAPA (BRASIL, 2006). Para fungos filamentosos e leveduriformes não existe legislação específica para o caso de fertilizantes orgânicos, portanto não apresenta condição como as demais. As amostras referentes aos três sistemas avaliados possuem tempo de permanência na composteira de 4 meses. Já a amostra controle definiu-se como tempo inicial igual a zero.

Avaliando a Tabela 1, pode-se observar que para o teste confirmativo de $E$. coli (EC) a amostra Controle apresentou NMP acima de 110, estando inadequada para utilização. No entanto, este se refere ao tempo inicial igual a zero. A presença destes microrganismos nesta amostra foi um resultado esperado que pode ser explicado pelo fato de não ter passado o tempo necessário para maturação na composteira. De acordo com a IN no 27 do MAPA referente a limites máximos e contaminantes admitidos em fertilizantes orgânicos, para o caso de $E$. coli o valor máximo admitido é NMP 1000,00 (BRASIL, 2006).

O restante das amostras apresentou um NMP bem inferior se comparado ao controle (NMP 2,3 para o sistema 1, NMP 46 para o sistema 2 e NMP 0,36 para o sistema 3). O que indica que com o passar do tempo parte dos patógenos são removidos pela maturação da compostagem. Isto pode ser confirmado observando as amostras dos três sistemas analisados, em que os valores para $E$. coli reduziram com quatro meses de tempo de permanência na composteira, sendo que o sistema 3 apresentou a maior redução, sendo este valor de 0,36. No entanto, pode-se observar que esta redução é semelhante à redução do sistema 1, que apresentou valor de 2,3. Nestes dois sistemas, ambos não apresentam cobertura, estando expostos ao clima.

Tabela 1 - Valores médios da avaliação microbiológica realizada com as condições de acordo com a IN 27/2006 do MAPA

\begin{tabular}{cccccc}
\hline Sistemas & $\begin{array}{c}\text { E. coli Condição: } \\
\text { Máximo admitido - NMP } \\
\mathbf{1 0 0 0 , 0 0}\end{array}$ & $\begin{array}{c}\text { Salmonella spp. } \\
\text { Condição: Ausência em } \\
\mathbf{1 0} \mathbf{g} \text { de amostra seca }\end{array}$ & $\begin{array}{c}\text { Fungos filamentosos e } \\
\text { leveduriformes }\end{array}$ \\
\hline $\begin{array}{c}\text { Controle } \\
\text { (tempo zero) }\end{array}$ & $>110$ & Inadequado & Presença & Inadequado & $5,1 \times 10^{2}-1,6 \times 10^{4}$ \\
\hline Sistema 1 & 2,3 & Adequado & Presença & Inadequado & $6,4 \times 10^{2}-2,4 \times 10^{4}$ \\
\hline Sistema 2 & 46 & Adequado & Presença & Inadequado & $3,6 \times 10^{2}-2,1 \times 10^{4}$ \\
\hline Sistema 3 & 0,36 & Adequado & Presença & Inadequado & $4,6 \times 10^{2}-5,2 \times 10^{4}$ \\
\hline
\end{tabular}

Fonte: Autores (2020)

No estudo desenvolvido por Orrico Junior, Orrico e Lucas Júnior (2009), sobre a eficiência da compostagem para remoção de coliformes totais e termotolerantes com o uso de dejetos suínos como substrato, foi verificado que ao final do processo de compostagem, $100 \%$ destes microrganismos foram eliminados, pois a temperatura permaneceu superior a $40 \stackrel{\circ}{\mathrm{C}}$ desde o início até o vigésimo dia de enleiramento. O pico da temperatura ocorreu no quinto dia quando atingiu $65^{\circ} \mathrm{C}$. 
Em relação a Salmonella spp. após o período de incubação em estufa observou-se o crescimento em todas as amostras analisadas (Figura 3). Neste caso, a exigência da legislação vigente é ausência da mesma em $10 \mathrm{~g}$ de matéria seca, segundo a IN № 27 do MAPA (BRASIL, 2006).

Figura 3 - Presença de Salmonella spp. nas amostras analisadas
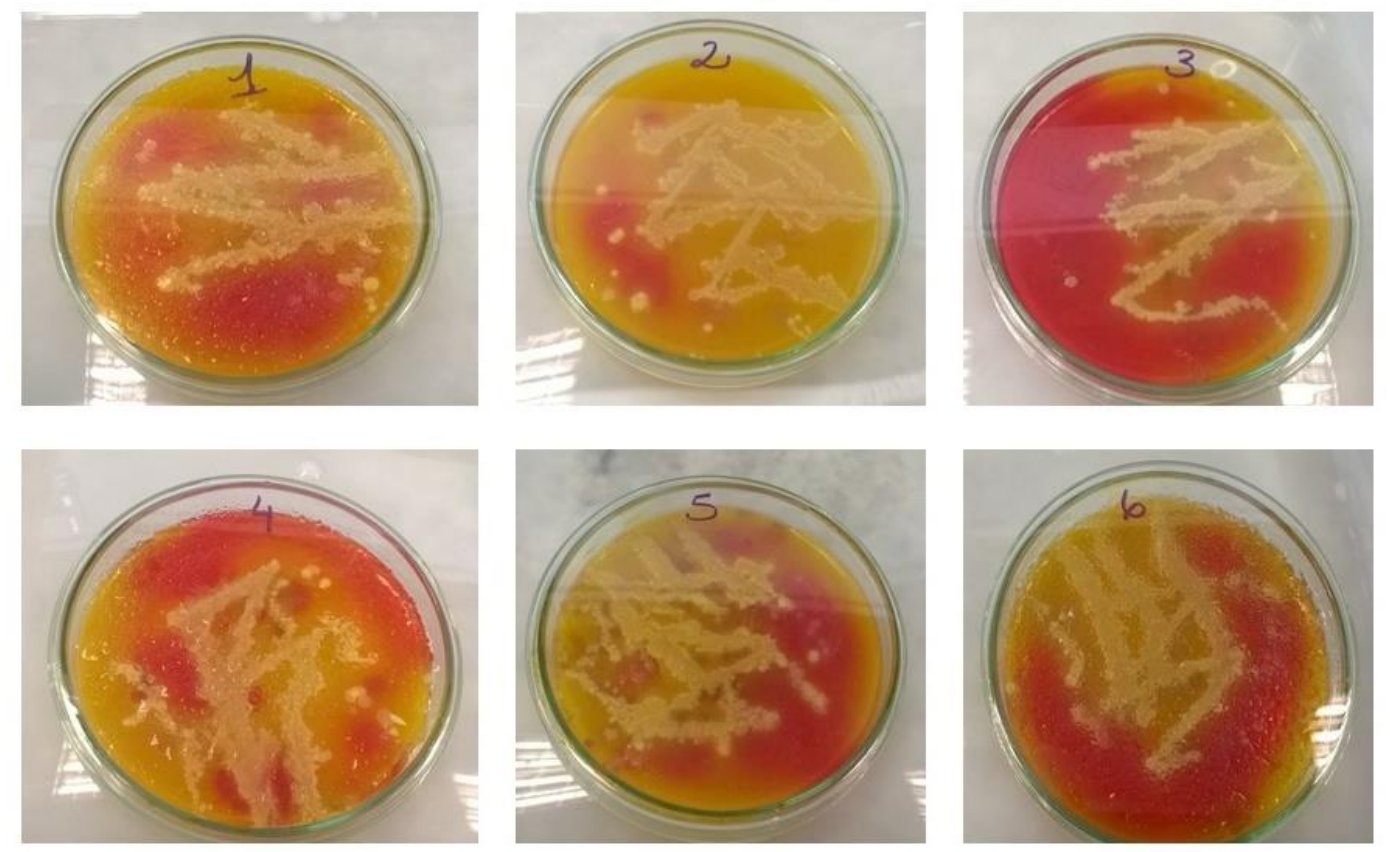

Fonte: Autores (2020)

Após o período de incubação na estufa observou-se o crescimento de Salmonella spp. e de E. coli em todas as amostras analisadas. De acordo com IN n ${ }^{\circ} 62$ da SDA/MAPA (BRASIL, 2003), a Salmonella spp. fermenta apenas a xilose levando a viragem do indicador de vermelho para amarelo por conta da produção de ácido. Pode ainda ocorrer a formação de colônias com centro negro. Apenas algumas amostras apresentaram pequenos pontos de cor marrom como a amostra 3, 4 e 5, enquanto a E. coli fermenta a lactose e desta forma produz colônias amarelas.

Apesar de não ser comum, houve o crescimento das duas espécies na mesma placa para todas as amostras (Figura 3). Isto se deve ao fato da escolha do meio de cultura, - Ágar XLD, que proporciona o crescimento tanto de E. coli e Salmonella spp. A presença de Salmonella spp. nas amostras dos três sistemas avaliados está ligada ao dejeto de diversas espécies animais, sendo mais comum a presença no dejeto de aves (AUGUSTO, 2016). No caso da Salmonella spp. se tem uma preocupação a mais pelo fato de causar problemas à saúde humana.

Apesar de não ser realizado o monitoramento da temperatura nos processos de compostagem em pequena escala, estudos mostram que os microrganismos possuem um tempo de sobrevivência ao calor. Os microrganismos da espécie Salmonella podem se multiplicar quando a temperatura estiver na faixa de $7^{\circ} \mathrm{C}$ a $49,5^{\circ} \mathrm{C}$, sendo $37 \stackrel{\circ}{\circ} \mathrm{C}$ a temperatura ideal de crescimento (GERMANO, P.M.L.; GERMANO, M.I.S., 2003). Ainda de acordo com os autores em cerca de 4 horas um alimento contaminado pode tornar-se infectante

No entanto, a Salmonella spp. pode ser inativada em até 60 minutos com temperatura de $55^{\circ} \mathrm{C}$ ou em até 15 minutos sujeita à temperatura de $60{ }^{\circ} \mathrm{C}$ (FLORES, 2011). Por isso é fundamental que o processo de compostagem permaneça na fase inicial com temperaturas acima de $55{ }^{\circ} \mathrm{C}$ para a inativação de patógenos (PEREIRA NETO; STENTIFORD, 1992). Além disso, é necessário um tempo mínimo de 18 dias para eliminação de Salmonella spp. com temperaturas termofílicas (PEREIRA NETO; STENTIFORD, 1992).

Grande parte destes microrganismos é eliminada se o processo da compostagem for monitorado e a temperatura chegar neste valor (CARLI, 2010). Porém, sabe-se que 


\section{REA - Revista de estudos ambientais (Online) v.22, n. 1, p.24-34, jan./jun. 2020}

caso não se atinja a temperatura necessária, os microrganismos patógenos não serão eliminados e irão sobreviver no solo ou na superfície das plantas durante um tempo. Bactérias como é o caso da Salmonella spp. sobrevivem de 2 meses a 1 ano no solo ou 1 mês a 6 meses na superfície de plantas (CARLI, 2010).

Neste estudo não foi verificada a remoção de Salmonella spp. ao final do processo de compostagem nos três sistemas avaliados. Estes resultados são preocupantes, visto que muitos produtores rurais utilizam estes sistemas em suas propriedades. A contaminação por Salmonella spp. pode oferecer riscos à saúde dos trabalhadores que manipulam este material e dos consumidores finais dos alimentos produzidos, principalmente hortaliças que são consumidas in natura.

Da mesma forma que a Salmonella spp., fungos filamentosos e leveduriformes também possuem um tempo de sobrevivência ao calor, conforme pode ser observado nos resultados encontrados neste estudo. Eles resistem a temperaturas em torno de $65,5^{\circ} \mathrm{C}$ durante 0,5 a 3 minutos (CARLI, 2010).

$\mathrm{O}$ alto valor na contagem de fungos filamentosos e leveduriformes pode estar relacionado com a deterioração em vegetais, principalmente os que possuem altos teores de umidade como o alface (FERREIRA et al., 2015). Este vegetal foi um dos resíduos utilizados como substrato no sistema 1, o que pode justificar a maior presença destes microrganismos nestas amostras.

A presença destes microrganismos também está relacionada à existência natural de diversos grupos de microrganismos durante o processo de compostagem. Logo após o preparo das leiras de compostagem podem ser observados microrganismos tais como bactérias aeróbias e anaeróbias, actinomicetes, fungos filamentosos e leveduriformes (PEPE; VENTORINO; BLAIOTTA, 2013). Estes últimos são de ocorrência natural nos processos de compostagem. Além disso, atribui-se a presença destes microrganismos a substratos com altos teores de açúcares como a canade-açúcar, resíduo presente no sistema 1 , que apresentou alta concentração de fungos filamentosos e leveduriformes.

Fazendo o comparativo entre as amostras analisadas dos três sistemas, notase que o controle do processo influencia consideravelmente na qualidade do composto final. O sistema 1 possui o diferencial de trabalhar com a vermicompostagem aliada a compostagem. De acordo com Albanell, Plaixats e Cabrero (1988) a vermicompostagem é capaz de estabilizar a matéria orgânica de forma mais rápida e obter assim um composto orgânico com relação carbono e nitrogênio $(\mathrm{C} / \mathrm{N})$ menor, se comparado a compostagem sem o uso de minhocas, dessa forma obtêm-se o composto em menor tempo.

As minhocas se alimentam preferencialmente de resíduos de origem animal provenientes das criações de bovinos, equinos, caprinos, suínos e ovinos que são consideradas excelentes fontes de matériaprima para criação de minhocas (STEFFEN et al., 2013). Com isso observa-se que a escolha do substrato e o uso da vermicompostagem melhoram a qualidade final do composto.

De acordo com a IN $n^{\circ} 27$ do MAPA (BRASIL, 2006), a presença de E. coli nas amostras analisadas dos 3 sistemas foi considerada adequada, portanto, dentro do limite estabelecido pela legislação.

Nos sistemas 2 e 3 as leiras de compostagem foram montadas na forma de pilhas e um fato que pode ter contribuído para a presença de E. coli (em baixas concentrações) é o próprio formato. De acordo com Augusto (2016), quando a compostagem é feita na forma de pilhas, a temperatura da porção central fica na faixa de $55{ }^{\circ} \mathrm{C}$ e na porção superficial bem abaixo deste valor. Por isso recomenda-se o revolvimento do material para que ocorra a introdução de oxigênio, favorecendo a atividade microbiana e dessa forma aumentando a temperatura da leira. Ainda, segundo os autores o ideal é que ocorra o revolvimento a cada 3 dias mantendo a temperatura acima de $55 \stackrel{\circ}{\mathrm{C}}$ durante 15 dias.

A partir dos resultados encontrados pode-se concluir que o controle no processo de compostagem é fundamental para a redução na presença de patógenos. A composteira do sistema 1 foi considerada 0 melhor processo dentre os três sistemas analisados. Isto porque o sistema 1 possui 0 controle da aeração através do revolvimento, considerada essencial num processo de compostagem e a vermicompostagem, apesar de apresentar um valor maior com relação a concentração de $E$. coli em comparação com o sistema 3. Para todos os casos recomenda-se 0 controle da temperatura, mantendo-a na faixa de $55^{\circ} \mathrm{C}$ para eliminação de microrganismos potencialmente patogênicos como $E$. coli e 
Salmonella spp. e o controle da aeração através de revolvimentos.

No entanto, para todos os sistemas avaliados neste estudo, provavelmente os mesmos não atingiram a temperatura necessária para eliminação de Salmonellla. Os compostos avaliados neste estudo foram obtidos após quatro meses de compostagem. O tempo inferior pode ter contribuído para positividade de Salmonella ao final do processo, pois a mesma possui um tempo de sobreviência de dois meses a um ano no solo ou um a seis meses na superfície das plantas, como visto anteriormente, o que acaba tornando-a mais resistente e persistente nos sistemas de compostagem.

Sugere-se, que mesmo em sistemas em pequena escala, realize-se a verificação da temperatura e medidas sejam adotadas para que a temperatura mínima de $55^{\circ} \mathrm{C}$ seja atingida. Há necessidade de inclusão de controles no processo como aeração para suprimento de oxigênio por meio de revolvimento da leira de compostagem e consequentemente manutenção da temperatura em faixas ótimas para estabilização do composto e eliminação de microrganismos patogênicos. O composto obtido nos três sistemas foi positivo para Salmonella no final do processo e pode oferecer um grande risco para a saúde pública. Assim, por meio dos resultados obtidos, mesmo havendo modificações no processo de compostagem os três sistemas não foram eficientes na remoção de Salmonella. Estes resultados podem contribuir para a melhoria nos sistemas de compostagem, uma vez que, eles muitas vezes não têm controle adequado podendo expor os trabalhadores e os consumidores a estes patógenos de grande importância para a saúde pública.

De acordo com Santos e Monteiro (2004) as informações referentes à contaminação microbiológica em alimentos orgânicos ainda são escassas. Por isso ainda existe a necessidade de mais estudos nessa área para preencher esta lacuna. Sabe-se que patógenos podem resistir no solo ou na superfície das plantas por um determinado tempo e consequentemente contaminando os alimentos que serão adubados com este composto (CARLI, 2010).

\section{Conclusões}

A partir dos resultados encontrados, nota-se a importância de controlar os parâmetros em processos de compostagem em pequena escala, o que não foi realizado neste estudo. Os resultados da análise microbiológica mostram que nos processos em que não são realizados controles, seja por meio do revolvimento da leira de compostagem para introdução de oxigênio, ou verificação da temperatura, para atingir temperaturas na faixa de $55 \mathrm{C}^{\circ}$, necessárias para eliminação de patógenos, a presença deles é maior. Neste caso houve permanência da Salmonella provavelmente poque os três sistemas acompanhados não atingiram a temperatura adequada para eliminação deste patógeno. Por fim, pode-se concluir que a pesquisa realizada trouxe contribuições pertinentes, tais como a redução da presença de $E$. colinos 3 sistemas analisados ao longo de quatro meses em comparação ao controle (tempo zero) e ainda a persistência na presença de Salmonella em todos os sistemas avaliados, sendo esta atribuída às baixas temperaturas do sistema de compostagem durante o período de estudo. Afirmando a necessidade de controle de temperatura na faixa de $55^{\circ} \mathrm{C}$ durante $\mathrm{o}$ processo de compostagem para eliminação destes patógenos. Dessa forma, medidas de controle devem ser adotadas a fim de melhorar os sistemas de compostagem, sem oferecer riscos à saúde pública.

\section{Microbiological evaluation in agro-industrial waste composting processes aiming at a good quality organic compost production}


for improvement in the composting systems used by small rural properties. The presence of Salmonella in the compounds of the three systems highlights the risk to public health and the need for standardization and improvement of the composting process used today.

Keywords: Composite; Potentially pathogenic microorganisms; Organic fertilizer.

\section{Referências}

ASSOCIAÇÃO BRASILEIRA DE NORMAS TÉCNICAS - ABNT. Bactérias coliformes totais, coliformes fecais e Escherichia coli em alimentos - Determinação do número mais provável (NMP): MB-3463. Rio de Janeiro: ABNT, 1991. 7p.

ASSOCIAÇÃO BRASILEIRA DE NORMAS TÉCNICAS - ABNT. NBR 10.007: Amostragem de resíduos sólidos. Rio de Janeiro: ABNT, 2004. $21 \mathrm{p}$.

ALBANELL, E.; PLAIXATS, J.; CABRERO, T. Chemical changes during vermicomposting (Eisenia fetida) of sheep manure mixed with cotton industrial wastes. Biology and Fertility of Soils, v. 6, n. 4, p. 266-269, 1988.

ALVARENGA, P.; PALMA, P.; GONÇALVES, A.P.; FERNANDES, R.M.; CUNHA-QUEDA, A.C.; DUARTE, E.; VALLINI, G. Evaluation of chemical and ecotoxicological characteristics of biodegradable organic residues for application to agricultural land. Environment International, v. 33, n. 4, p. 505-513, 2007.

ALVARENGA, P.; MOURINHA, C.; FARTO, M.; SANTOS, T.; PALMA, P.; SENGO, J.; MORAIS, M.-C.; CUNHA-QUEDA, C. Sewage sludge, compost and other representative organic wastes as agricultural soil amendments: benefits versus limiting factors. Waste Management, v. 40, p. 4452, 2015.

AMORIM, A. C.; LUCAS JÚNIOR, J.; RESENDE, K. T. Compostagem e vermicompostagem de dejetos de caprinos: efeitos das estações do ano. Engenharia Agrícola, Jaboticabal, v. 25, n.1, p.5766, jan/abr, 2005. Disponível em: https://www.scielo.br/pdf/eagri/v25n1/24871.pdf.

Acesso em: 07 dez. 2020.

ANDREOLLI, C.V. Tratamento e disposição do lodo de esgoto no Paraná. Sanare, v. 1, p. 10-15, Curitiba, 1994.

AUGUSTO, K. V. Z. Eliminação de patógenos no esterco através da compostagem. Avicultura industrial. Campinas, 2016. Disponível em: https://www.aviculturaindustrial.com.br/imprensa/e liminacao-de-patogenos-no-esterco-atraves-dacompostagem-por-karolina-von-zubenaugusto/20110815-141325-Z913. Acesso em: 24 nov. 2018.
BRASIL. Instrução Normativa no 27, de 05 de junho de 2006. Diário Oficial da União, Ministério da Agricultura, Pecuária e Abastecimento, Brasília, DF, 09 jun. 2006. Seção 1, p. 15.

BRASIL. Instrução Normativa $n^{\circ} 62$, de 26 de agosto de 2003. Diário Oficial da União, Ministério da Agricultura, Pecuária e Abastecimento, Secretaria de Defesa e Agropecuária, Brasília, DF, 18 set. 2003. Seção 1, p. 14.

CARLI, S. T. Uso de Degradadores Biológicos na Aceleração do Processo de Compostagem dos Resíduos Orgânicos Vegetais e Palhas de Embalagem - Estudo de Caso na CeasaCuritiba. 2010. 159 f. Trabalho de Conclusão de Curso - Faculdade de Ciências Exatas da Universidade Tuiuti do Paraná, Curitiba, 2010. Disponível em: http://www.ceasa.pr.gov.br/arquivos/File/TCC_US O_DEGRADADORES_BIOLOGICOS.pdf. Acesso em: 19 out. 2018.

CESARO, A.; CONTE A.; BELGIORNO, V.; SICILIANO, A.; GUIDA, M. The evolution of compost stability and maturity during the full-scale treatment of the organic fraction of municipal solid waste. Journal of Environmental Management, v. 232 , p. 264-270, 2019.

CHOWDHURY, M.A.; DE NEERGAARD, A.; JENSEN, L.S. Potential of aeration flow rate and bio-char addition to reduce greenhouse gas and ammonia emissions during manure composting. Chemosphere, v. 97, p. 16-25, 2014.

FOOD AND AGRICULTURE ORGANIZATION OF THE UNITED NATIONS - FAO., 2020. The State of Food Security and Nutrition in the world. Disponível em:

http://www.fao.org/3/ca9692en/online/ca9692en.ht ml\#chapter-1_1. Acesso em: 14 set. 2020.

FAVERIAL, J.; BOVAL, M.; SIERRA, J.; SAUVANT, D. End-product quality of composts produced under tropical and temperate climates using different raw materials: a meta-analysis. Journal of Environmental Management, v. 183, p. 909-916, 2016.

FERREIRA, M. B.; BORDIN, L. C.; TEIXEIRA, B. K.; MODEL, B. P.; NETTO, R. G. S.; NESPOLO, C. R. Contaminação microbiológica em alfaces comercializadas na Fronteira Oeste do Rio Grande do Sul. In: SIMPÓSIO DE SEGURANÇA ALIMENTAR E SAÚDE, 5., 2015, Bento Gonçalves. Anais... Bento Gonçalves: UFRGS, 
2015. p. 1-4. Disponível em: http://www.ufrgs.br/sbctars-

eventos/gerenciador/painel/trabalhosversaofinal/S AL119.pdf. Acesso em: 29 nov. 2018.

FLORES, J. P. Avaliação da utilização de fezes caninas em composteiras de pequena escala. 2011, 97 f. Dissertação (Mestrado em Meio Ambiente Urbano e Industrial) - Setor de Engenharia Química da Universidade Federal do Paraná, Serviço Nacional de Aprendizagem Industrial e Universitat Sttutgart, Curitiba-PR, 2011. Disponível em: http://dspace.c3sl.ufpr.br/dspace/bitstream/handle/ 1884/29344/R\%20-\%20D\%20-

\%20JULIENE\%20PAIVA\%20FLORES.pdf?seque nce $=1$. Acesso em: 12 out. 2018.

GERMANO, P.M.L.; GERMANO, M.I.S. Agentes bacterianos de toxinfecções. Higiene e vigilância de Alimentos. 2. ed, São Paulo: Varela, 2003, p. 216-265.

GUO, R.; LI, G., JIANG, T.; SCHUCHARDT, F.; CHEN, T.; ZHAO, Y.; SHEN, Y. Effect of aeration rate, $\mathrm{C} / \mathrm{N}$ ratio and moisture content on the stability and maturity of compost. Bioresource Technology, v. 112, p. 171-178, 2012.

INSTITUTO NACIONAL DE METEOROLOGIA INMET. Ministério da Agricultura, Pecuária e Abastecimento. 2020. Disponível em: https://portal.inmet.gov.br/. Acesso em: 11 set. 2020.

ISMAEL, L. L.; PEREIRA, R. A.; FARIAS, C. A. S.; FARIAS, E. T. R. Avaliação de composteiras para reciclagem de resíduos orgânicos em pequena escala. Revista Verde de Agroecologia e Desenvolvimento Sustentável, v. 8, n. 4, p. 2839, 2013.

ORRICO JUNIOR, M. A. P.; ORRICO, A. C. A.; LUCAS JUNIOR, J.. Compostagem da fração sólida da água residuária de suinocultura. Eng. Agríc, Jaboticabal, v. 29, n. 3, jul-set. 2009. Disponível em: http://www.scielo.br/scielo.php?script=sci_arttext\& pid=S0100-69162009000300015. Acesso em: 20 abr. 2016.

KIEHL, E. J. Fertilizantes orgânicos. São Paulo: Agronômica Ceres, 1985. 492p.

LIMA, J.; REZENDE, F. A.; COSTA, C. R.; NEWPORT, A. M. Rede de cooperação no êxito de iniciativas voltadas para a utilização de composto orgânico na produção de hortaliças por pequenos agricultores em Camaçari-Ba. Revista Brasileira de Agroecologia, v. 3, n. 3, p. 47-52, 2008.

MARAGNO, E. S.; TROMBIN, D. F.; VIANA, E. O Uso da Serragem no Processo de Minicompostagem. Revista Engenharia Sanitária e Ambiental, v. 12, n. 4, p. 355-360, 2007.
MARROCOS, S. T. P.; JUNIOR, J. N.; GRANGEIRO, L. C.; AMBROSIO, M. M. Q.; CUNHA, A. P. A. Composição química e microbiológica de biofertilizantes em diferentes tempos de decomposição. Revista Caatinga, v. 25, n. 4, p. 34-43, out-dez, 2012.

MEJIAS, L.; KOMILIS, D.; GEA, T.; SÁNCHEZ, A. The effect of airflow rates and aeration mode on the respiration activity of four organic wastes: implications on the composting process. Waste Management, v. 65, p. 22-28, 2017.

MEENA, M. D.; JOSHI, P. K.; JAT, H. S.; CHINCHMALATPURE, A. R.; NARJARY, B.; SHEORAN, P.; SHARMA, D. K. Changes in biological and chemical properties of saline soil amended with municipal solid waste compost and chemical fertilizers in a mustard-pearl millet cropping system. Catena, v. 140, p. 1-8, 2016.

MENDES, A. A; CINTRÃO, J. F. F. Os resíduos de serviços de saúde - RSS e a questão ambiental. Revista Uniara, n.15, p. 121-134, 2004.

NUNES, M. U. C. Compostagem de Resíduos para Produção de Adubo Orgânico na Pequena Propriedade. Aracaju: Embrapa Tabuleiros Costeiros, 2009, 7 p. (Embrapa Tabuleiros Costeiros. Circular Técnica, 59).

ONWOSI, C.O.; IGBOKWE, V.C.; ODIMBA, J.N.; EKE, I.E.; NWANKWOALA, M.O.; IROH, I.N.; EZEOGU, L.I. Composting technology in waste stabilization: on the methods, challenges and future prospects. Journal of Environmental Management, v. 190, p. 140-157, 2017.

PEPE, O; VENTORINO, V; BLAIOTTA, G. Dynamic of functional microbial groups during mesophilic composting of agro-industrial wastes and free-living (N2)-fixing bacteria application. Waste Management, v. 33, n. 7, p. 1616-1625, 2013.

PEREIRA, R. A. Compostagem em pequena escala e uso do composto como substrato na germinação de sementes de tomate (Lycopersicum esculentum). 2013. 56 f. Dissertação (Mestrado em Sistemas Agroindustriais) - Universidade Federal de Campina Grande (CCTA/UFCG), Pombal-PB, 2013.

PEREIRA NETO, J.T.; STENTIFORD, E.I. Aspectos epidemiológicos da compostagem. Revista de Biologia, Uberlândia, v.1, n.1, p.1-6, 1992.

PÉREZ, D.V.; ALCANTARA, S.; RIBEIRO, C.C.; PEREIRA, R.E.; FONTES, G.C.; WASSERMAN, M.A.; VENEZUELA, T.C.; MENEGUELLI, N.A.; DE MACEDO, J.R.; BARRADAS, C.A.A. Composted municipal waste effects on chemical properties of a Brazilian soil. Bioresource Technology, v. 98, p. 525-533, 2007. 
RASAPOOR, M.; ADL, M.; POURAZIZI, B. Comparative evaluation of aeration methods for municipal solid waste composting from the perspective of resource management: a practical case study in Tehran, Iran. Journal of Environmental Management, v. 184, p. 528-534, 2016.

SANTOS, G. C.; MONTEIRO, M. Sistema orgânico de produção de alimentos. Alimentos e Nutrição, v.15, n.1, p.73-86, 2004.

SILVA, N.; JUNQUEIRA, V. C. A.; SILVEIRA, N. F. A. Manual de métodos de análise microbiológica de alimentos. $2^{\circ}$ ed. São Paulo: Livraria Varela, 2001.

STEFFEN, G. P. K., ANTONIOLLI, Z. I., STEFFEN, R. B., JACQUES, R. J. S. Importância ecológica e ambiental das minhocas. Revista de Ciências Agrárias, v. 36, n. 2, 2013. Disponível em: <http://www.scielo.mec.pt/pdf/rca/v36n2/v36n2a02 .pdf >. Acesso em: $08 \mathrm{dez} .2020$.

WANGEN, D. R. B.; FREITAS, I. C. V. Compostagem doméstica: alternativa de aproveitamento de resíduos sólidos orgânicos. Revista Brasileira de Agroecologia, v. 5, n. 2, p. 81-88, 2010.

\section{Agradecimentos}

Coordenação de Aperfeiçoamento de Pessoal de Nível Superior - CAPES, Conselho Nacional de Desenvolvimento Científico e Tecnológico - CNPQ, Fundação de Amparo à Pesquisa do Estado do Rio Grande do Sul - FAPERGS e Centro de Apoio e Promoção da Agroecologia - CAPA e Universidade Federal da Fronteira Sul UFFS. 